\title{
Ankle-Foot Continuous Passive Motion Device for Mobilization of Acute Stroke Patients
}

\author{
Csilla Vér ${ }^{1}$, Gergely Hofgárt ${ }^{1}$, László Menyhárt² ${ }^{2}$ László Kardos ${ }^{3}$, László Csiba ${ }^{1}$ \\ ${ }^{1}$ Department of Neurology, University of Debrecen, Debrecen, Hungary \\ ${ }^{2}$ Medical Systems Hungary Ltd., Debrecen, Hungary \\ ${ }^{3}$ Kenézy Gyula County Hospital, Debrecen, Hungary \\ Email: vercsilla10@gmail.com
}

Received 5 February 2015; accepted 31 March 2015; published 3 April 2015

Copyright (C) 2015 by authors and Scientific Research Publishing Inc.

This work is licensed under the Creative Commons Attribution International License (CC BY). http://creativecommons.org/licenses/by/4.0/

\section{Abstract}

Purpose: To develop a continuous passive motion (CPM) device for the passive motion of the paretic ankle-foot and investigate the effect of continuous passive motion of bedridden, hemiparetic acute stroke patients. Methods: 49 patients with stroke were investigated. Results in stroke patients (device group) were compared with those of 15 control subjects (manual group) also with stroke but not treated by device. The period of the treatment was 7 days; the duration was 30 minutes per day by CPM device in the device group. The efficacy of the device was evaluated by scales used in the clinical routine $\left(6^{\text {th }}\right.$ item of National Institutes of Health Stroke Scale (NIHSS), Modified Ashworth Scale (MAS), modified Rankin Scale (mRS)). Ankle's passive range of motion (PROM) and flexible equinovalgus deformitiy were measured every day with a goniometer. Results: $6^{\text {th }}$ item of NIHSS score improved by $-0.76(S D=0.56)$ points in the device group $(p<0.001)$ compared to the baseline values; the mean change in the manual group was $-0.33(\mathrm{SD}=0.62)$ points $(p=0.055)$. The mean of MAS decreased significantly by $-0.53(S D=1.12)$ point in the device group ( $<<0.001)$. The ankle's mean plantar flexion PROM increased by 3.41 (SD $=5.19$ ) degrees in the device group $(p<0.001)$. Significant improvement of the mean dorsiflexion in the PROM of the ankle was also detected $(p=0.019)$. The equinovalgus improved significantly by $-5.12(S D=8.02)$ degrees $(p<0.001)$ in the device group. The scores of the $m R S$ also improved significantly in the device group $(p<0.001)$. Conclusion: In the early phase of rehabilitation, ankle-foot continuous passive motion device treatment combined with manual therapy improved the ankle's PROM better than manual therapy alone; in addition, device treatment decreased the foot's equinovalgus, improved the $6^{\text {th }}$ item NIHSS score, and decreased the severity of spasticity.

\section{Keywords}

Stroke, Ankle, Continuous Passive Motion, Equinovalgus 


\section{Introduction}

Stroke is an important health care issue resulting in chronic disability and its early rehabilitation is still a challenge.

The most common motor impairment is the hemiparesis of the upper and lower limb. The impaired lower limb is a major challenge in the rehabilitation of post stroke patients.

Caused by circulatory disturbance, the paresis endangers patients in terms of survival and improvement outlooks. Spasticity, deep venous thrombosis, and decubitus ulcers can all be contributed to by the decreased ability of lower leg movements [1].

In stroke patients, spasticity disrupts the functional use of weakened muscles mainly in the distal joints of the paretic lower limb. Structural changes to muscle fibers and connective tissue may contribute to alterations in intrinsic mechanical properties [2].

Several studies reported spasticity rates of $4 \%$ to $27 \%$ in the early time course (1 to 4 weeks); moreover, Lundstörm et al. and Sommerfeld et al. detected spasticity in the first week after first ever-stroke [3]-[5].

Following stroke, paresis in the dorsiflexor muscles that raise the foot and move the ankle during walking results in the plumping down of the foot after heel strike, and lugging toes during swing [2].

Moreover, there is a strong relationship between ankle plantar flexor weakness and knee hyperextension during the midstance phase [6].

All these complications may cause unsafe gait, accidental falls, and fractures such as hip fractures; also, these dysfunctions may provoke additional complications such as contractures and/or deformities [2].

Common deformities following stroke are equinovarus, equinus, and equinovalgus deformities. Equinovarus is caused by spasticity in the plantar flexors and invertors, and paresis of the dorsiflexors and evertors of the foot. Equinus is caused by the spasticity of the three-headed calf muscle (triceps surae) [7].

Equinovalgus is also a frequent finding; the base and the heel are rotated away from the midline. It can be a flexible or a fixed deformity.

Equinovalgus is caused by spasticity in the gastrocnemius, soleus, and peroneus brevis muscles [8], and weakness of the tibialis anterior and tibialis posterior muscles. These dysfunctions result in external rotation of the foot during the gait cycle, and create instability at push-off. Contractures and loss of passive ankle range of motion are common problems after stroke [9]-[11].

Gracies investigated the time course of muscle contracture. In mouse soleus muscles, after only 24 hours of unloading, there was a $60 \%$ shortening of muscle fiber length, and evidence of sarcomere disorganization [12].

Muscle shortening caused by reduced joint mobility increase the resistance to passive joint movement, and can provoke deformities and pain [13].

Active and passive movement (by a physiotherapist) of the paretic leg is essential for rehabilitation and for prevention or improvement of spasticity and contractures.

Due to a world-wide shortage of physiotherapists (especially on weekends and holidays), the demand for simple devices that can replace or at least assist physiotherapists is increasing.

To meet this challenge was our main motivation for developing the device.

The second aim of our study was to measure whether our device therapy with manual therapy are as effective as manual therapy (or even better) in acute stroke patients.

The ankle-foot continuous passive motion device passively moves the paretic foot (plantar and dorsiflexion) and is equipped with a special alarm system to prevent extreme extension or flexion.

The frequency and amplitude of the movement can be adapted to the patient's personal needs; mobilization can be automatically stopped if the patient requires an increase or decrease of mobilizing strength or frequency.

\section{Methods}

\subsection{Participants}

Forty-nine acute ischaemic and haemorrhagic stroke patients (mean age: 62.2 years (SD = 12.38); female/male distribution: 18/31) were treated by manual therapy and by ankle-foot CPM device every day for a week (device group).

Our control group (manual group) consisted of 15 acute stroke patients (mean age: 71.3 years $(\mathrm{SD}=10.39$ ); female/male distribution: 7/8) who did not receive treatment with the ankle-foot CPM device, only manual 
therapy by a physiotherapist.

Demographic and clinical data are summarized in Table 1.

Manual and ankle-foot CPM device therapy were started between 24 and 48 hours after stroke.

Inclusion criteria: acute ischemic or hemorrhagic stroke confirmed by clinical investigations and computed tomography in the device and manual groups.

All patients were bedridden and suffering from hemiparesis with modified Rankin Scale (mRS) 3 to 5 [14].

None of our patients were able to get out of bed without assistance.

Definition of mild and moderate paresis ( $6^{\text {th }}$ item of National Institutes of Health Stroke Scale (NIHSS)):

1) Point: drift; leg falls by the end of the 5 -second period but does not hit the bed

2) Points: some effort against gravity; leg falls to bed by 5 seconds but has some effort against gravity

Definition of severe paresis ( $6^{\text {th }}$ item of NIHSS):

3) Points: no effort against gravity; leg falls to bed immediately

4) Points: no movement [15].

Patients were excluded from investigation for the following reasons: primary brain tumor, brain metastasis, Parkinson's disease, multiple sclerosis, rheumatoid arthritis, ankylosis of the ankle or foot joints, trauma or surgery of the foot or ankle; patients with chronic stroke symptoms or psychiatric symptoms were also excluded.

No patients received oral or parenteral antispastic therapy (e.g. botulinum toxin).

The study was approved by the Regional and Institutional Ethics Committee (DE OEC RKEB/IKEB 37722012) and each patient gave written informed consent.

\subsection{The Ankle-Foot Continuous Passive Motion Device}

The ankle-foot continuous passive motion device (prototype device) mobilizes the paretic foot repeatedly across the ankle's entire range of motion between plantar and dorsiflexion (up to 60 degrees).

Angle, power and speed parameters were individually adapted to the patients in the device group in order to reach maximum motion intensity below the pain threshold.

If the device detects active resistance, movement is stopped automatically. During the investigation, neither the extension nor the flexor motion was observed to reach the threshold of pain.

Measuring $25 \times 52 \times 45 \mathrm{~cm}$ and weighing $7 \mathrm{~kg}$, the device is optimal for bedside use (Figures 1-3).

The ankle-foot continuous passive motion device is driven by a 24-volt direct current (DC) motor. The operating frequency range extremes are 7 times per minute from plantar to dorsiflexion (altogether 60 degrees) at maximum speed and 4 times per minute from plantar to dorsiflexion at minimum speed.

Resistance parameters were typically set between 1 to $7 \mathrm{Nm}$ maximum resistance torque in dorsiflexion, and 1 to $10 \mathrm{Nm}$ maximum resistance torque in plantar flexion.

\subsection{Randomization and Treatment Procedures}

Our study consisted of two periods. In the first period, patients received standard physiotherapy (manual therapy in the manual group). Subsequently, treatment was supplemented by the ankle-foot continuous passive motion device in the second period (device group).

Patients were assigned to groups randomly, consecutively according to selection criteria.

In both groups (before and after any therapy) the Modified Ashworth Scale, modified Rankin Scale, $6^{\text {th }}$ item

Table 1. Characteristics of patients in the manual and device groups.

\begin{tabular}{|c|c|c|c|}
\hline \multicolumn{4}{|c|}{ Manual group } \\
\hline Female/Male & Ischemic/hemorrhagic stroke & Moderate paresis/severe paresis & Age (mean) \\
\hline $\begin{array}{l}7 / 8 \text { subjects } \\
(p=0.553)\end{array}$ & $\begin{array}{l}11 / 4 \text { subjects } \\
(p=1.000)\end{array}$ & $\begin{array}{l}8 / 7 \text { subjects } \\
(p=0.553)\end{array}$ & $\begin{array}{c}71.3 \text { years }(S D=10.39) \\
(p=0.013)\end{array}$ \\
\hline \multicolumn{4}{|c|}{ DEVICE GROUP } \\
\hline Female/Male & Ischemic/hemorrhagic stroke & Moderate paresis/severe paresis & Age (mean) \\
\hline $\begin{array}{l}18 / 31 \text { subjects } \\
(p=0.553)\end{array}$ & $\begin{array}{l}37 / 12 \text { subjects } \\
\quad(p=1.000)\end{array}$ & $\begin{array}{l}\text { 20/29 subjects } \\
\quad(p=0.553)\end{array}$ & $\begin{array}{c}62.2 \text { years }(S D=12.38) \\
(p=0.013)\end{array}$ \\
\hline
\end{tabular}




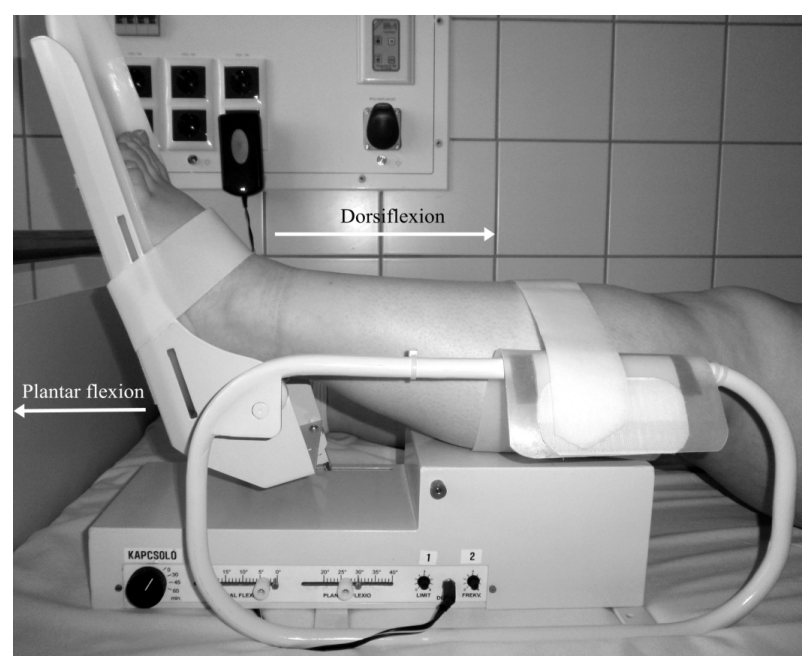

Figure 1. The ankle-foot continuous passive motion device.

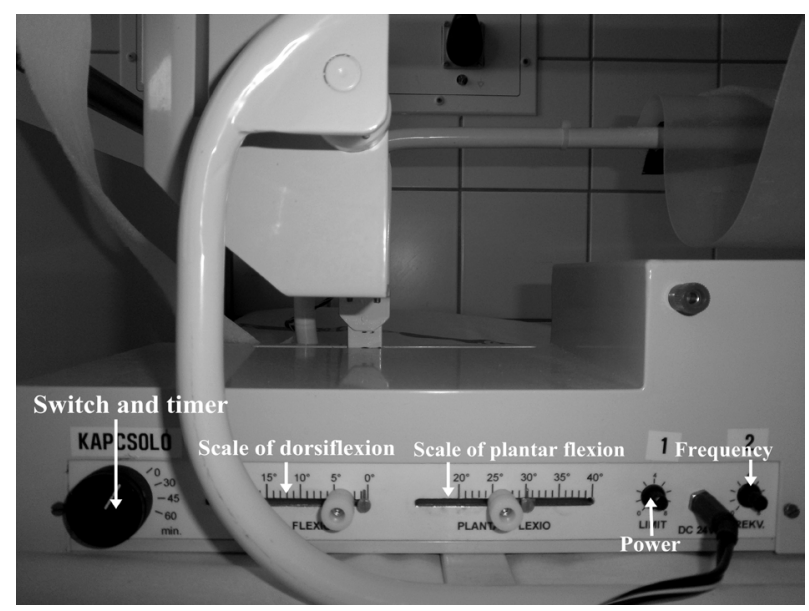

Figure 2. Control unit of the ankle-foot continuous passive motion device.

of NIHSS and goniometer measurements were performed.

We used the goniometer for measurements of the range (in degrees) of motion of passive ankle plantar or dorsiflexion, and flexible equinovalgus deformity before and after treatment.

During the assessment of passive range of motion, the ankle was in a neutral position with the knee fully extended and the hip in a neutral position (i.e. the hip was not in rotation). The neutral position of the ankle is at 90 degrees between the leg and the foot (Figure 4 and Figure 5). Active range of motion and muscle strength was not measured.

The daily duration of ankle-foot continuous passive motion device therapy was 30 minutes on the paretic limb; the average total treatment period was 5.5 days (range 4 to 7 ).

Consisting of 11 items, the National Institutes of Health Stroke Scale quantifies clinical status impaired by stroke. The $6^{\text {th }}$ item of NIHSS only evaluates lower leg movements [15].

A separate evaluation of the $6^{\text {th }}$ item was necessary because other items (e.g. facial nerve, gaze etc) are not necessarily related to the improvement or worsening of lower leg status, but might obscure changes specific to our anatomical region of interest.

We investigated the spasticity of the soleus muscle because the soleus muscle plays an important role in plantar flexion of the foot and maintaining a standing position. The Modified Ashworth Scale is a quick and easy way to measure spasticity [16] (Figure 6).

The modified Rankin Scale evaluates the degree of disability or dependence in the daily activities of post 


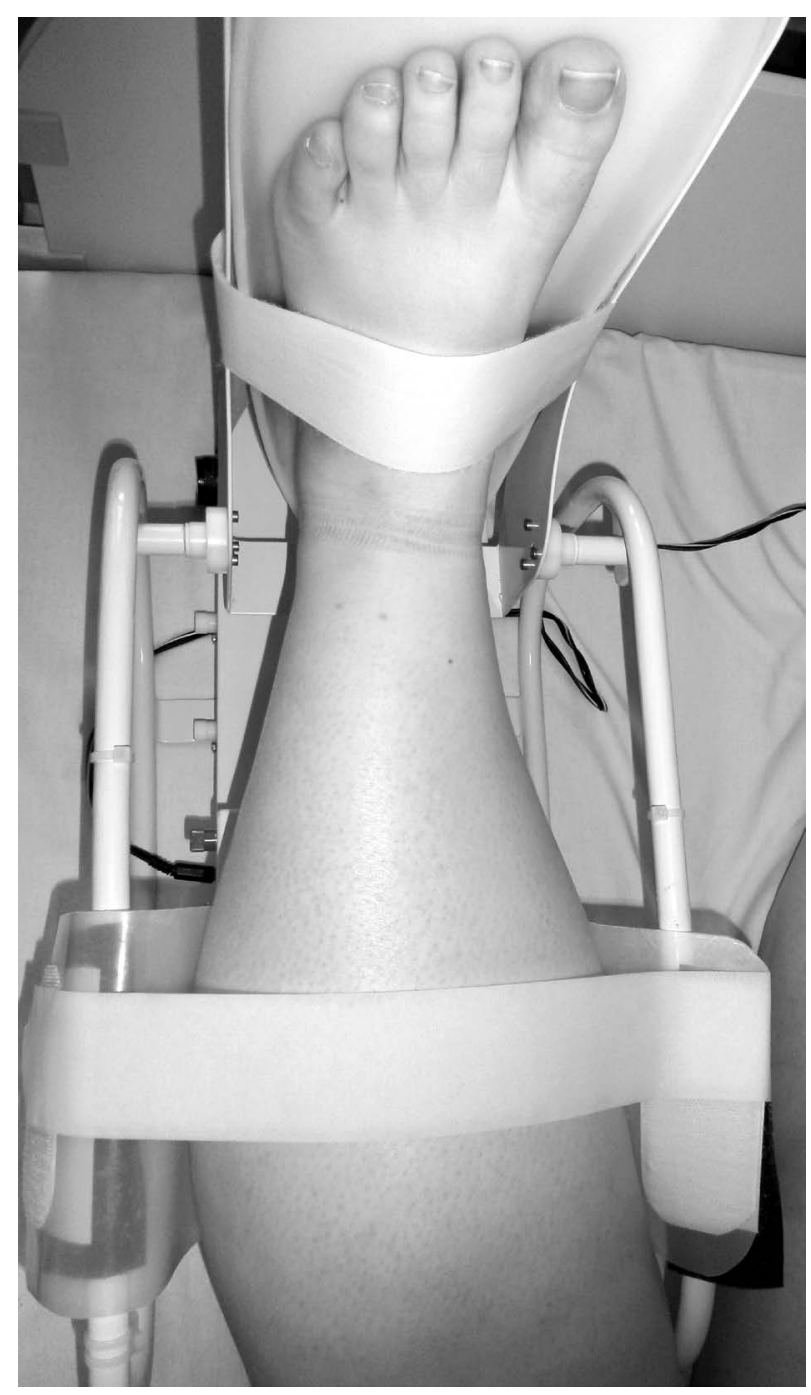

Figure 3. Plan view of the ankle-foot continuous passive motion device.

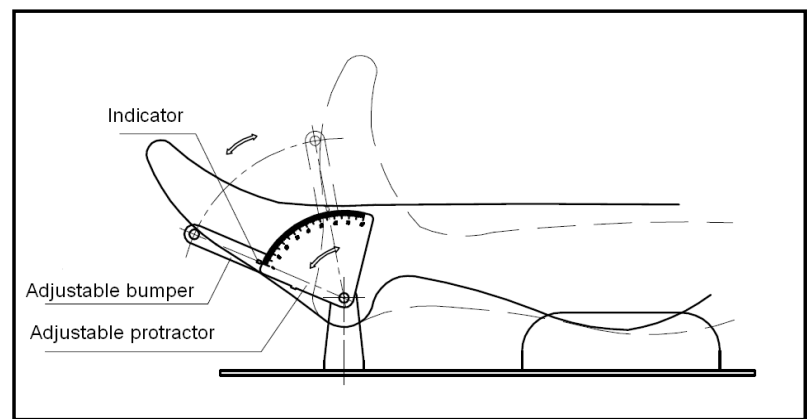

Figure 4. The goniometer. Measurement of the passive range of plantar and dorsiflexion. The term "passive range of motion" refers to the radius of motion achieved by external force without using the patient's own muscles.

stroke patients or patients with other neurological disabilities.

The scale runs 0 to 6 , from perfect health without symptoms to death [14] (Figure 7). 


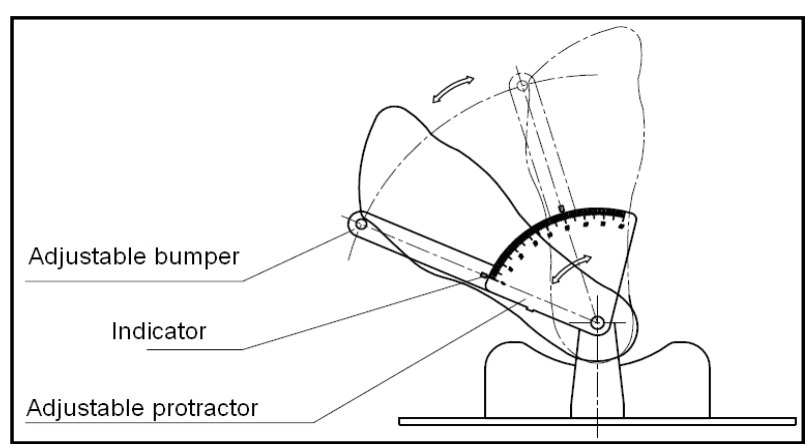

Figure 5. Measurement of the flexible equinovalgus deformity of the foot.

\begin{tabular}{|l|}
\multicolumn{1}{c|}{ Modified Ashworth Scale } \\
0 point: No increase in muscle tone \\
1 point: Slight increase in muscle tone, manifested by a catch and release or by minimal resistance at the \\
end of the range of motion when the affected part(s) is moved in flexion or extension \\
2 points: Slight increase in muscle tone, manifested by a catch, followed by minimal resistance \\
throughout the remainder (less than half) of the ROM \\
3 points: More marked increase in muscle tone through most of the ROM, but affected part(s) easily \\
moved \\
4 points: Considerable increase in muscle tone, passive movement difficult \\
5 points: Affected part(s) rigid in flexion or extension.
\end{tabular}

Figure 6. Score definitions of the Modified Ashworth Scale.

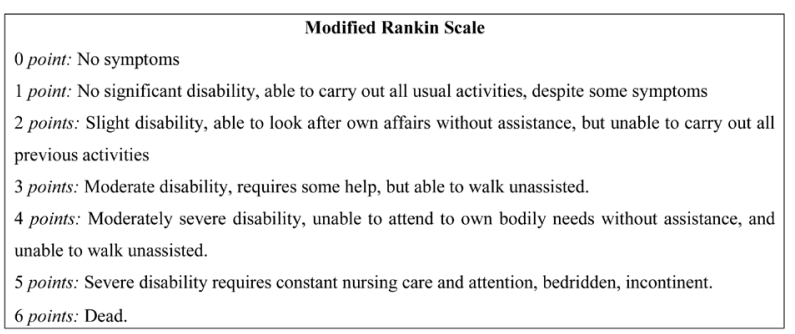

Figure 7. Score definitions of the modified Rankin Scale.

\subsection{Statistical Analysis}

Within-subject differences were calculated by subtracting baseline values from pre-session measurements of the last available session, and tested for significance using Student's paired t tests or Wilcoxon's matched-pairs signedranks tests, subject to normality assumptions being satisfied or not. The statistical package Stata was used for data analysis [17].

\section{Results}

Because of the wide individual variability of the passive range of motion and equinovalgus position, first we compared patient by patient changes before and after therapy, then we evaluated the differences and compared them with those observed in the manual group.

\subsection{Important Observations in the Manual Group (Compared to Baseline Values)}

The mean NIHSS score improved by an average $-1.00(\mathrm{SD}=1.77)$ point, the median (IQR) absolute difference being $-1(-2$ to 0$)(p=0.046)$.

The improvement of the $6^{\text {th }}$ item (NIHSS) did not reach the level of significance $(p=0.055)$.

No significant changes could be detected in the plantar $(p=0.349)$ and dorsiflexion $(p=0.456)$.

The improvement of equinovalgus deformity $(p=0.485)$ and Modified Ashworth Scale $(p=0.499)$ was not significant (Table 2). 
Table 2. Changes (absolute difference and relative improvement) after therapy compared with baseline values in NIHSS, NIHSS $6^{\text {th }}$ item, passive range of motion (plantar and dorsiflexion), degree of equinovalgus deformity and Modified Ashworth Scale score.

\begin{tabular}{|c|c|c|c|c|c|c|}
\hline Outcome & $\begin{array}{l}\text { Patient } \\
\text { group }\end{array}$ & $\begin{array}{l}\text { Mean absolute } \\
\text { difference }\end{array}$ & Mean relative improvement & $\begin{array}{l}\text { Median absolute } \\
\text { difference }\end{array}$ & $\begin{array}{c}\text { Median relative } \\
\text { improvement }\end{array}$ & p value \\
\hline \multirow{2}{*}{ NIHSS } & Manual & $-1.00(\mathrm{SD}=1.77)$ & $11.5 \%(\mathrm{SD}=17.4)$ & $-1(-2$ to 0$)$ & $8.3 \%(0.0$ to 18.2$)$ & 0.046 \\
\hline & Device & $-2.27(\mathrm{SD}=2.47)$ & $20.7 \%(\mathrm{SD}=21.9)$ & $-2(-3$ to -1$)$ & $16.7 \%$ (7.7 to 28.6$)$ & $<0.001$ \\
\hline \multirow[t]{2}{*}{ NIHSS $6^{\text {th }}$ item } & Manual & $-0.33(\mathrm{SD}=0.62)$ & $11.1 \%(\mathrm{SD}=38.1)$ & $0(-1$ to 0$)$ & $0.0 \%(0.0$ to 50.0$)$ & 0.055 \\
\hline & Device & $-0.76(\mathrm{SD}=0.56)$ & $27.4 \%(S D=24.6)$ & $-1(-1$ to 0$)$ & $25.0 \%$ (0.0 to 33.3$)$ & $<0.001$ \\
\hline \multirow[t]{2}{*}{ Plantar flexion } & Manual & $0.93(\mathrm{SD}=3.73)$ & $8.6 \%(\mathrm{SD}=22.6)$ & - & - & 0.349 \\
\hline & Device & $3.41(\mathrm{SD}=5.19)$ & $29.6 \%(\mathrm{SD}=67.8)$ & - & - & $<0.001$ \\
\hline \multirow[t]{2}{*}{ Dorsiflexion } & Manual & $0.67(\mathrm{SD}=3.27)$ & $43.3 \%(\mathrm{SD}=121.8)$ & - & - & 0.456 \\
\hline & Device & $1.15(\mathrm{SD}=2.71)$ & $28.4 \%(\mathrm{SD}=52.2)$ & - & - & 0.019 \\
\hline \multirow[t]{2}{*}{ Equinovalgus } & Manual & $0.93(\mathrm{SD}=5.04)$ & $0.1 \%(\mathrm{SD}=52.8)$ & - & - & 0.485 \\
\hline & Device & $-5.12(\mathrm{SD}=8.02)$ & $33.4 \%(\mathrm{SD}=65.4)$ & - & - & $<0.001$ \\
\hline \multirow[t]{2}{*}{ MAS } & Manual & $0.13(\mathrm{SD}=0.74)$ & $0.8 \%(\mathrm{SD}=53.1)$ & $0(0$ to 1$)$ & $0.0 \%(-33.3$ to 25.0$)$ & 0.499 \\
\hline & Device & $-0.53(\mathrm{SD}=1.12)$ & $29.7 \%(\mathrm{SD}=57.6)$ & $0(-1$ to 0$)$ & $33.3 \%(0.0$ to 50.0$)$ & $<0.001$ \\
\hline
\end{tabular}

None of our patients (in either group) developed any complications such as pneumonia or deep venous thrombosis/pulmonary embolism.

The changes in equinovalgus, dorsiflexion and plantar flexion before first session and before last session in the manual and device groups are shown in Figures 8-10.

\subsection{Important Observations in the Device Group (Compared to Baseline Values)}

The mean NIHSS score improved by an average of $-2.27(\mathrm{SD}=2.47)$ points, the median (IQR) absolute difference being $-2(-3$ to -1$)(\mathrm{p}<0.001)$.

The mean NIHSS $6^{\text {th }}$ item score of the lower limb also improved significantly by an average of -0.76 (SD $=$ 0.56 ) points ( $\mathrm{p}<0.001)$; the median (IQR) absolute difference was -1 ( -1 to 0$)(\mathrm{p}<0.001)$.

The passive range of motion of the ankle plantar flexion increased massively by an average of 3.41 ( $\mathrm{SD}=$ 5.19) degrees in the device group $(\mathrm{p}<0.001)$ and significant improvement of the mean dorsiflexion in the PROM of the ankle was also detected $(\mathrm{p}=0.019)$.

The mean equinovalgus deformity decreased by $5.12(\mathrm{SD}=8.02)$ degrees $(\mathrm{p}<0.001)$.

The mean Modified Ashworth Scale score improved by -0.53 (SD = 1.12) point; the median absolute difference was 0 ( -1 to 0$)$ ( $\mathrm{p}<0.001)$ (Table 2$)$.

The changes in modified Rankin Scale before and after treatment are shown in Figure 11 and Figure 12.

\section{Discussion}

Stroke may lead to spasticity, contracture, reduced joint range of motion, and lower limb deformity [11] [18] [19].

To our knowledge, this is the first study to evaluate the efficacy of a passive plantar and dorsiflexion device for the reduction of flexible equinovalgus deformity and ankle spasticity in acute stroke patients. Spasticity with or without other complications (e.g. equinovalgus, Achilles contracture, etc.) has a negative impact on global outcome after stroke [20].

Therefore, prevention and therapy of contracture or abnormal foot position is of high priority. Besides pharmacotherapy, passive mobilization and stretching of the paretic lower extremity is one of the options. Regular mobilization helps prevent contractures and reduce spasticity [21].

A number of publications have reported about the positive impact of stretching on connective tissue prolifera- 


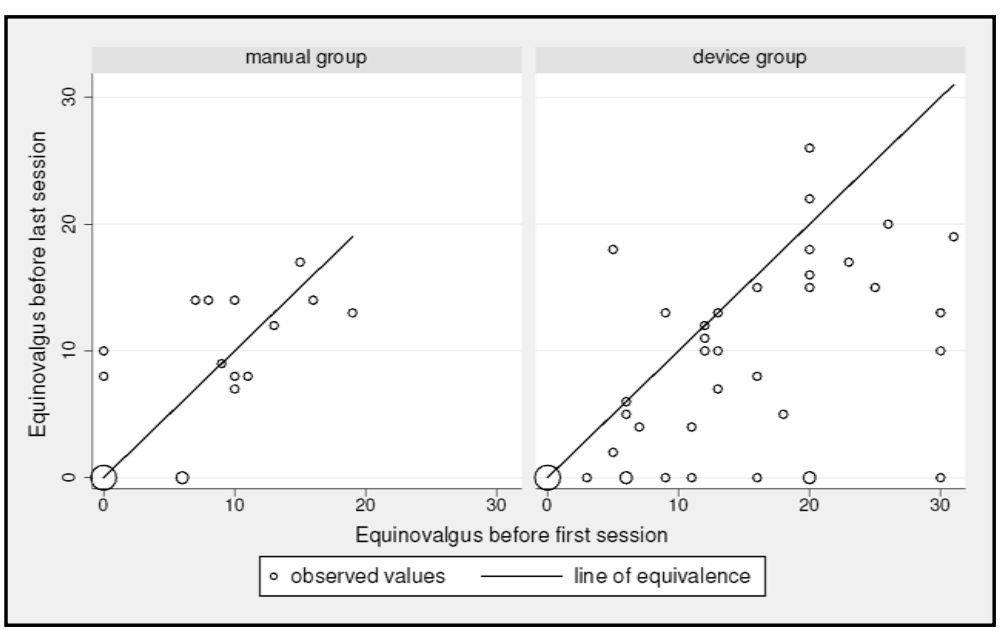

Figure 8. Degree of equinovalgus before first and before last session in the manual and device groups.

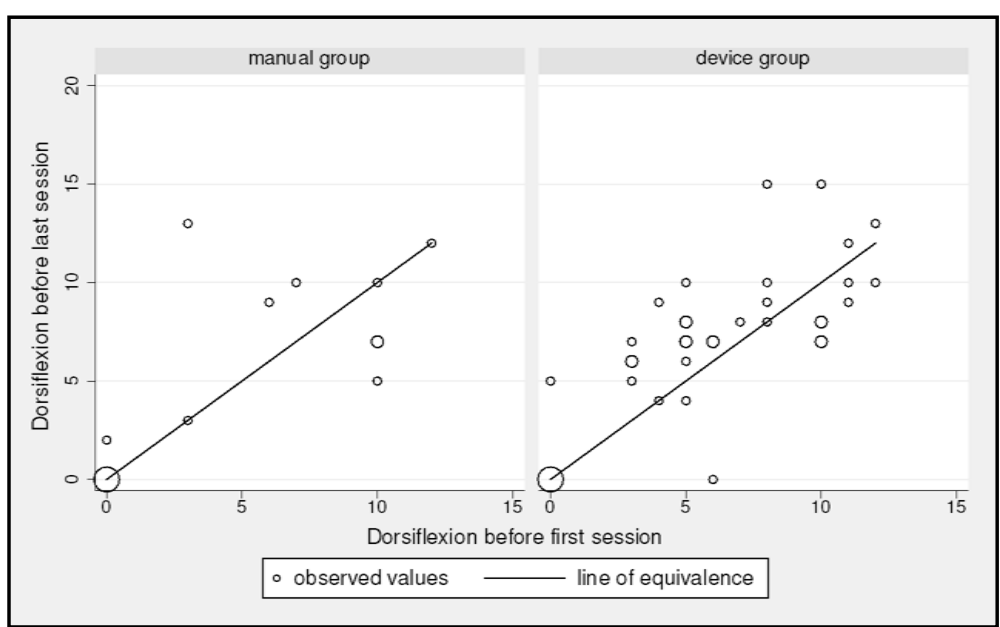

Figure 9. Degree of dorsiflexion passive range of motion before first and before last session in the manual and device groups.

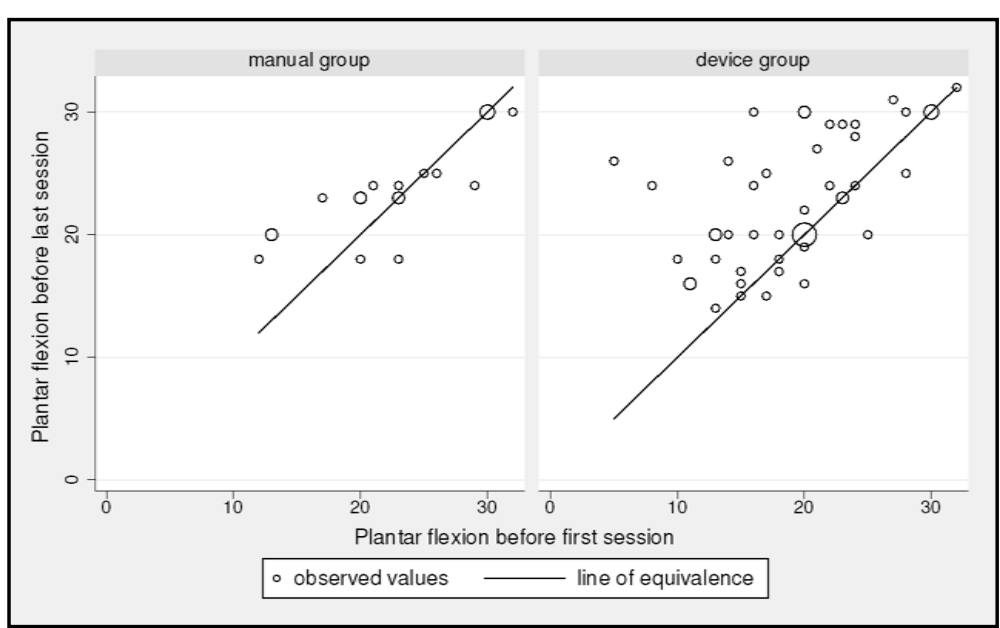

Figure 10. Degree of plantar flexion passive range of motion before first and before last session in the manual and device groups. 


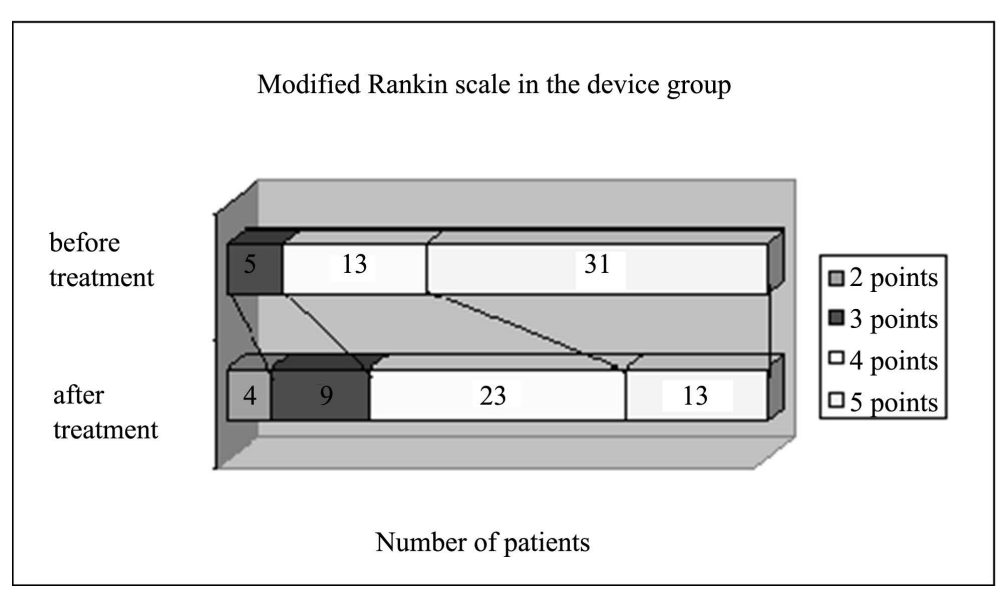

Figure 11. Functional outcome on the modified Rankin Scale in the device group.

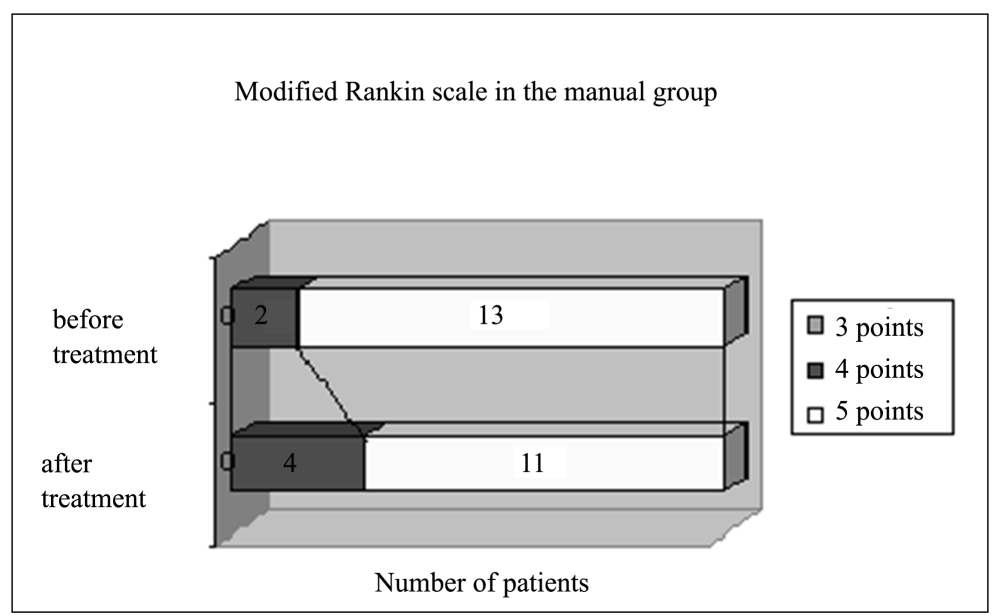

Figure 12. Functional outcome on the modified Rankin Scale in the manual group.

tion, muscle fiber atrophy, and serial sarcomere loss in immobilized muscles of mice [22]-[24].

Gomes et al. investigated the effect of passive stretch, applied for 30 minutes to the rat soleus muscle, on myogenic differentiation (myoD) and they found that a single session of passive stretching increased myoD gene expression, a factor related to muscle growth [25].

Kamikawa et al. have proposed passive stretching to preserve skeletal muscle tone in patients who are unconscious or paralyzed [26].

However, manual motion or stretching requires permanent physiotherapist presence and participation, and treatment efficacy depends on her/his skill to measure range of motion limits or "end feel" [27].

Passive motion devices can be effective alternatives to manual passive motion because they also improve the ankle's range of motion [28] and deformities of the foot.

Similar devices have already been developed for passive mobilization of chronic stroke patient's ankle joints [27] [29] [30].

However, contrary to our work, none of the cited articles tested the new device on acute, bedridden stroke patients (the earliest treatment onset in the cited articles was 7 months after stroke), and none of the publications report a test battery as complex as the one we used for evaluation (passive range of motion before and after therapy, modified Ashworth Scale, equinovalgus, modified Rankin Scale, 6th item of NIHSS, NIHSS). Our device is designed to be used on bedridden patients (as the majority of stroke patients is bedridden in the acute phase), while the majority of the devices published about so far could be used only on standing or sitting pa- 
tients [27] [29] [30], which is extremely difficult in the acute phase of stroke.

Contrary to Wu et al., Zhang et al., and Selles et al., we studied not only the improvement of gait, reflexes, or Ashworth scale, but also the impact of treatment on global outcome scales such as NIHSS and modified Rankin Scale to verify the usefulness of our device on acute stroke patients in a more complex manner [27] [29] [30]. Our device is user friendly because it is easy to carry to the patient's bed and adjustable to individual treatment needs (angles, power, and speed); and when the device detects a resistance, it stops automatically. The therapy did not result in any pain or injury.

As far as we know, there is no similar device in available literature that was tested on acute stroke patients and proved to be useful for daily bedside application through an evaluation scheme as complex as described above.

A noteworthy observation is that not only was therapy by the device as effective as the manual approach, but better in terms of some investigated parameters:

1) In the manual group, the passive range of motion of plantar and dorsiflexion, equinovalgus deformity of the foot, and modified Ashworth Scale score did not change significantly, while the same parameters improved significantly in the device group.

2) In the device group, where we performed manual therapy as well, our ankle-foot continuous passive motion device also significantly improved disability scores such as NIHSS score, $6^{\text {th }}$ item of NIHSS score, and modified Rankin Scale score, while in the manual group, only NIHSS score improved.

The explanation could lie in the fact that, as known from literature, passive movement of a paretic limb can elicit flow and/or metabolic changes in the corresponding cortical and/or subcortical area of the contralateral hemisphere. Motor recovery (induced by arm training) has been observed to be associated with distinct changes of brain activation (regional cerebral blood flow increase as ascertained via positron emission tomography) in bilaterally distributed sensory and motor systems [31]. Activation during passive movement could also be detected in the contralateral primary motor, sensory cortices, and in premotor cortical and subcortical regions by functional MRI [32].

Carel et al. found that prolonged passive training of the wrist can change the cortical representation of passive movements and induce over-activation of the primary sensorimotor cortex and supplementary motor areas in healthy subjects as assessed by functional MRI.

Carel et al. [33] and Weiller et al. [34] detected much more widespread cortical and subcortical activation by passive movement of the wrist or elbow than Mima et al. [35] observed; in the latter study, the middle finger was moved passively, and activation could only be detected in the contralateral cortical somatosensory area.

We hypothesize that the reason why cortical and subcortical activation is more intense by mobilization with the device than by only manual mobilization is because the device is characterized by a greater stability in strength, frequency, and form of repetition parameters. Moreover, the stimulation surface is larger (the device stimulates the whole surface of the foot, as opposed to contact area limitations inherent in manual therapy).

In summary, the advantages of our ankle-foot continuous passive motion device are:

- Lightweight and easy to use;

- Personalized therapy (adjustable angles, power, and speed);

- Bedside application on bedridden patients;

- No risk for patients (automatically stops in case of overextension or flexion);

- Potential applications for quantitative evaluation of antispastic therapy.

The limitations of the device and of this study include:

- The plane of movement of the ankle-foot device is confined to the sagittal plane;

- We do not know how long the effect of the treatment lasts;

- In this study, we applied semi-quantitative clinical scales;

- We investigated a heterogeneous sample of stroke patients, similarly to most of the available literature.

\section{References}

[1] Adams Jr., H.P., Adams, R.J., Brott, T., del Zoppo, G.J., Furlan, A., Goldstein, L.B., Grubb, R.L., Higashida, R., Kidwell, C., Kwiatkowski, T.G., Marler, J.R. and Hademenos, G.J. (2003) Guidelines for the Early Management of Patients with Ischemic Stroke. A Scientific Statement from the Stroke Council of the American Stroke Association. Stroke, 34, 1056-1083. http://dx.doi.org/10.1161/01.STR.0000064841.47697.22

[2] Roy, A., Forrester, L.W., Macko, R.F. and Krebs, H.I. (2013) Changes in Passive Ankle Stiffness and Its Effects on 
Gait Function in People with Chronic Stroke. Journal of Rehabilitation Research \& Development, 50, 555-572. http://dx.doi.org/10.1682/JRRD.2011.10.0206

[3] Wissel, J., Manack, A. and Brainin, M. (2013) Toward an Epidemiology of Poststroke Spasticity. Neurology, 80, S13S19. http://dx.doi.org/10.1212/WNL.0b013e3182762448

[4] Lundström, E., Smits, A., Terént, A. and Borg, J. (2010) Time-Course and Determinants of Spasticity during the First Six Months Following First-Ever Stroke. Journal of Rehabilitation Medicine, 42, 296-301. http://dx.doi.org/10.2340/16501977-0509

[5] Sommerfeld, D.K., Eek, E.U., Svensson, A.K., Holmqvist, L.W. and von Arbin, M.H. (2004) Spasticity after Stroke: Its Occurrence and Association with Motor Impairments and Activity Limitations. Stroke, 35, 134-139. http://dx.doi.org/10.1161/01.STR.0000105386.05173.5E

[6] Cooper, A., Alghamdi, G.A., Alghamdi, M.A., Altowaijri, A. and Richardson, S. (2012) The Relationship of Lower Limb Muscle Strength and Knee Joint Hyperextension during the Stance Phase of Gait in Hemiparetic Stroke Patients. Physiotherapy Research International, 17, 150-115. http://dx.doi.org/10.1002/pri.528

[7] Proper, B.A. (1982) Rehabilitation after a Stroke. The Journal of Bone and Joint Surgery, 64, 156-163.

[8] Morrell, D.S., Pearson, J.M. and Sauser, D.D. (2002) Progressive Bone and Joint Abnormalities of the Spine and Lower Extremities in Cerebral Palsy. Radiographics, 22, 257-268. http://dx.doi.org/10.1148/radiographics.22.2.g02mr19257

[9] Dudek, N. and Trudel, G. (2008) Joint Contractures. In: Frontera, W.R., Silver, J.K. and Rizzo Jr., T.D., Eds., Essentials of Physical Medicine and Rehabilitation, 2nd Edition, Saunders Elsevier, Philadelphia, 117. http://dx.doi.org/10.1016/B978-1-4160-4007-1.50119-X

[10] O’Dwyer, N.J., Ada, L. and Neilson, P.D. (1996) Spasticity and Muscle Contracture Following Stroke. Brain, 119, 17371749. http://dx.doi.org/10.1093/brain/119.5.1737

[11] Kwah, L.K., Harvey, L.A., Diong, J.H. and Herbert, R.D. (2012) Half of the Adults Who Present to Hospital with Stroke Develop at Least One Contracture within Six Months: An Observational Study. Journal of Physiotherapy, 58, 41-47. http://dx.doi.org/10.1016/s1836-9553(12)70071-1

[12] Gracies, J.M. (2005) Pathophysiology of Spastic Paresis. I: Paresis and Soft Tissue Changes. Muscle \& Nerve, 31, 535551. http://dx.doi.org/10.1002/mus.20284

[13] Katalinic, O.M., Harvey, L.A. and Herbert, R.D. (2011) Effectiveness of the Stretch for the Treatment and Prevention of Contractures in People with Neurological Conditions: A Systematic Review. Physical Therapy, 91, 11-24. http://dx.doi.org/10.2522/ptj.20100265

[14] Banks, J.L. and Marotta, C.A. (2007) Outcomes Validity and Reliability of the Modified Rankin Scale: Implications for Stroke Clinical Trials: A Literature Review and Synthesis. Stroke, 38, 1091-1096. http://dx.doi.org/10.1161/01.str.0000258355.23810.c6

[15] Brott, T., Adams Jr., H.P., Olinger, C.P., Marler, J.R., Barsan, W.G., Biller, J., Spilker, J., Holleran, R., Eberle, R. and Hertzberg, V. (1989) Measurements of Acute Cerebral Infarction: A Clinical Examination Scale. Stroke, 20, 864-870. http://dx.doi.org/10.1161/01.str.20.7.864

[16] Gorgey, A., Chiodo, A.E., Zemper, E.D., Hornyak, J.E., Rodriguez, G.M. and Gater, D.R. (2010) Relationship of Spasticity to Soft Tissue Body Composition and the Metabolic Profile in Persons with Chronic Motor Complete Spinal Cord Injury. Journal of Spinal Cord Medicine, 33, 6-15.

[17] StataCorp (2009) Stata Statistical Software: Release 11. StataCorp LP., College Station.

[18] Bell, K.R. and Vandenborne, K. (1998) Contracture and Limb Deformities. In: Lazar, R.B., Ed., Principles of Neurologic Rehabilitation, McGraw-Hill, New York, 309-328.

[19] Rymer, W.Z. and Katz, R.T. (1994) Mechanisms of Spastic Hypertonia. Physical Medicine and Rehabilitation: State of the Art Reviews, 8, 441-451.

[20] Sunnerhagen, K.S., Olver, J. and Francisco, G.E. (2013) Assessing and Treating Functional Impairment in Poststroke Spasticity. Neurology, 80, S35-S44. http://dx.doi.org/10.1212/wnl.0b013e3182764aa2

[21] Katz, R.T. (1991) Management of Spastic Hypertonia after Stroke. Neurorehabilitation and Neural Repair, 5, S5-S12. http://dx.doi.org/10.1177/136140969100500502

[22] Williams, P.E. (1998) Effect of Intermittent Stretch on Immobilized Muscle. Annals of the Rheumatic Diseases, 47, 1014-1016. http://dx.doi.org/10.1136/ard.47.12.1014

[23] Goldspink, G. (1999) Molecular Mechanism Involved in the Determination of Muscle Fiber Mass and Phenotype. Advances in Exercise and Sports Physiology, 5, 27-39.

[24] Goldspink, G., Williams, P. and Simpson, H. (2002) Gene Expression in Response to Muscle Stretch. Clinical Ortho- 
paedics and Related Research, 403, S146-S152. http://dx.doi.org/10.1097/00003086-200210001-00017

[25] Gomes, A.R., Soares, A.G., Peviani, S., Nascimento, R.B., Moriscot, A.S. and Salvini, T.F. (2006) The Effect of 30 Minutes of Passive Stretch of the Rat Soleus Muscle on the Myogenic Differentiation, Myostatin, and Atrogin-1 Gene Expressions. Archives of Physical Medicine and Rehabilitation, 87, 241-246. http://dx.doi.org/10.1016/j.apmr.2005.08.126

[26] Kamikawa, Y., Ikeda, S., Harada, K., Ohwatashi, A. and Yoshida, A. (2013) Passive Repetitive Stretching for a Short Duration within a Week Increases Myogenic Regulatory Factors and Myosin Heavy Chain mRNA in Rats' Skeletal Muscles. Scientific World Journal, 2013, Article ID: 493656. http://dx.doi.org/10.1155/2013/493656

[27] Selles, R.W., Li, X., Lin, F., Chung, S.G., Roth, E.J. and Zhang, L.Q. (2005) Feedback-Controlled and Programmed Stretching of the Ankle Plantarflexors and Dorsiflexors in Stroke: Effects of a 4-Week Intervention Program. Archives of Physical Medicine and Rehabilitation, 86, 2330-2336. http://dx.doi.org/10.1016/j.apmr.2005.07.305

[28] Gao, F. (2010) Development of Motorized Facilitated Ankle Stretching. http://www.asbweb.org/conferences/2010/abstracts/40.pdf

[29] Wu, C.L., Huang, M.H., Lee, C.L., Liu, C.W., Lin, L.J. and Chen, C.H. (2006) Effect on Spasticity after Performance of Dynamic-Repeated-Passive Ankle Joint Motion Exercise in Chronic Stroke Patients. Kaohsiung Journal of Medical Sciences, 22, 610-617. http://dx.doi.org/10.1016/s1607-551x(09)70361-4

[30] Zhang, L.Q., Chung, S.G., Bai, Z., Xu, D., van Rey, E.M., Rogers, M.W., Johnson, M.E. and Roth, E.J. (2002) Intelligent Stretching of Ankle Joints with Contracture/Spasticity. IEEE Transactions on Neural Systems and Rehabilitation Engineering, 10, 149-157. http://dx.doi.org/10.1109/TNSRE.2002.802857

[31] Nelles, G., Jentzen, W., Jueptner, M., Müller, S. and Diener, H.C. (2001) Arm Training Induced Brain Plasticity in Stroke Studied with Serial Positron Emission Tomography. Neuroimage, 13, 1146-1154. http://dx.doi.org/10.1006/nimg.2001.0757

[32] Ciccarelli, O., Toosy, A.T., Marsden, J.F., Wheeler-Kingshott, C.M., Sahyoun, C., Matthews, P.M., Miller, D.H. and Thompson, A.J. (2005) Identifying Brain Regions for Integrative Sensorimotor Processing with Ankle Movements. Experimental Brain Research, 166, 31-42. http://dx.doi.org/10.1007/s00221-005-2335-5

[33] Carel, C., Loubinoux, I., Boulanouar, K., Manelfe, C., Rascol, O., Celsis, P. and Chollet, F. (2000) Neural Substrate for the Effects of Passive Training on Sensorimotor Cortical Representation: A Study with Functional Magnetic Resonance Imaging in Healthy Subjects. Journal of Cerebral Blood Flow \& Metabolism, 20, 478-484. http://dx.doi.org/10.1097/00004647-200003000-00006

[34] Weiller, C., Jüptner, M., Fellows, S., Rijntjes, M., Leonhardt, G., Kiebel, S., Müller, S., Diener, H.C. and Thilmann, A.F. (1996) Brain Representation of Active and Passive Movements. Neuroimage, 4, 105-110. http://dx.doi.org/10.1006/nimg.1996.0034

[35] Mima, T., Sadato, N., Yazawa, S., Hanakawa, T., Fukuyama, H., Yonekura, Y. and Shibasaki, H. (1999) Brain Structures Related to Active and Passive Finger Movements in Man. Brain, 122, 1989-1997. http://dx.doi.org/10.1093/brain/122.10.1989 